\title{
中国广西柳江红花二线船闸下引航道高边坡 预应力针索施工技术与质量控制
}

\author{
Construction Technology and Quality Control of Prestressed Anchor Cable on High Slope of \\ Lower Approach Channel of Honghua Second Line Shiplock in Liujiang, Guangxi, China \\ 符业晃
}

Yehuang $\mathrm{Fu}$

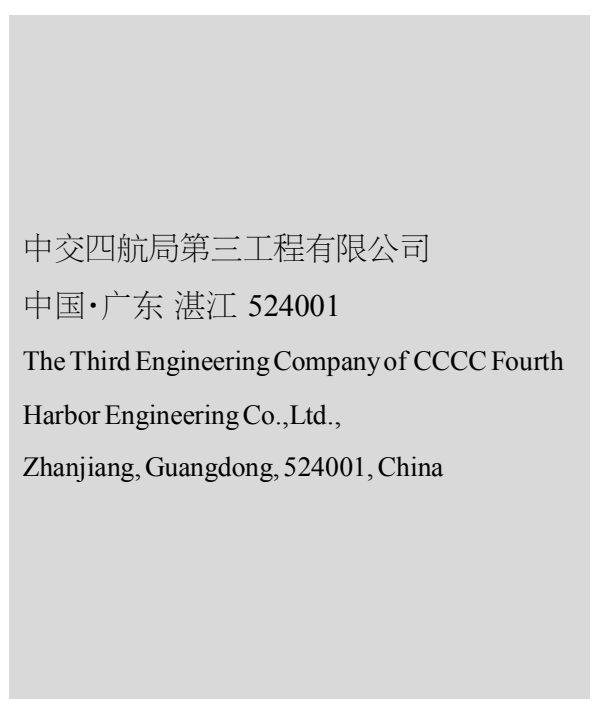

【摘要】论文以中国广西柳江红花水利枢纽二线船闸工程为例, 对船闸施工中高边坡预 应力锚索的施工技术和质量控制措施进行了研究, 对工程的重难点和施工基本流程进行 了阐述和分析, 并制定了施工中的质量保证措施, 期待能够为中国船闸工程中预应力锚索 的施工提供参考。

【Abstract】Taking the second-line ship lock project of Honghua Water Control Project in Liujiang, Guangxi, China as an example, the paper studies the construction technology and quality control measures of prestressed anchor cable in high slope during ship lock construction, elaborates and analyzes the major and difficult points of the project and the basic construction process, and formulates quality assurance measures during construction, hoping to provide reference for the construction of prestressed anchor cable in China's ship lock project.

【关键词】船闸工程; 预应力锚索; 施工技术; 质量控制

【Keywords \ship lock project; prestressed anchor cable; construction technology; quality control 【DOI】10.36012/etr.v2i4.1699

\section{1 引言}

预应力针是指利用预应力技术, 将针索固定在岩体内部, 用以加固边坡 ${ }^{[1]}$ 。预应力针索通过将不稳固的岩体和稳固的 岩体固定在一起, 可以提升岩体整体的稳定程度, 从而保障施 工的安全。因此研究预应力针索的高边坡支护施工,对于保障 船闸施工的有序进行和人员安全具有重要意义。

\section{2 工程简介}

中国柳江红花水利枢纽二线船闸工程土建 III标位于柳州 里雍镇红花村, 布置在已建的红花水利枢纽一线船闸的左侧, 两线船闸中心距为 $120 \mathrm{~m}$, 按 2000t 级船闸(兼顾通航 $3000 \mathrm{t}$ 级 船舶, 按 II 级船闸 )建设, 船闸有效尺度为 $280 \mathrm{~m} \times 34 \mathrm{~m} \times 5.8 \mathrm{~m}$ (长×宽 $\times$ 门槛水深), 船闸主体段总长 $387 \mathrm{~m}$, 其中上闸首长 $52 \mathrm{~m}$, 闸室长 $270 \mathrm{~m}$, 下闸首长 $65 \mathrm{~m}$ 。针索的布置拟定在下游航 道 1+200 船 1+318 高程 、 $1+246$ 高程和 $1+246$ 船 $1=318$ 高程, 具体的布置平面如图 1 所示。

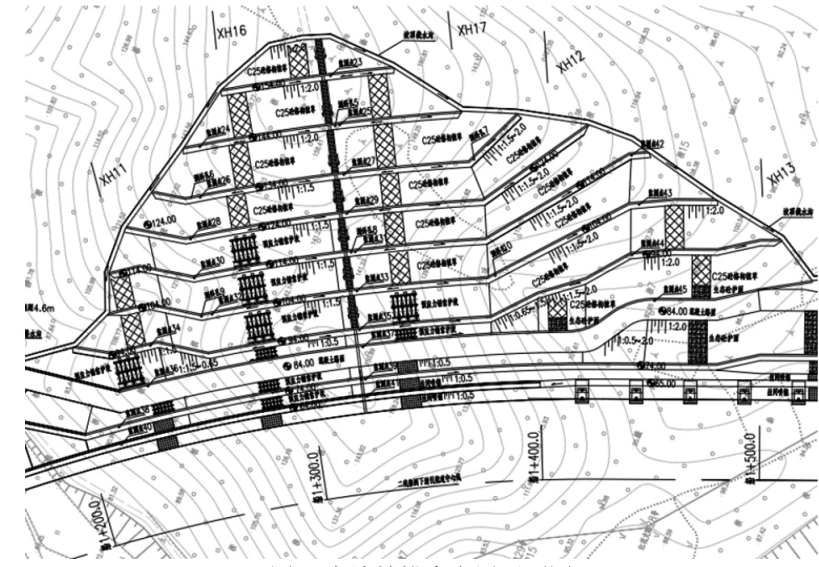

图 1 高边坡针索布置平面图

\section{3 主要施工工艺方案}

\section{1 方案思路}

本工程中的针索采用压力分散型针索, 成梅花形布置, 针 索的间距为 $4 \mathrm{~m}$, 针固长度为 $12 \mathrm{~m}$, 单根针索的预计承受压力 
为 $1600 \mathrm{kN}$ 。因此, 每根针索中布置 4 级承载力为 $400 \mathrm{kN}$ 的承 载体。具体的针索支护结构如图 2 所示。

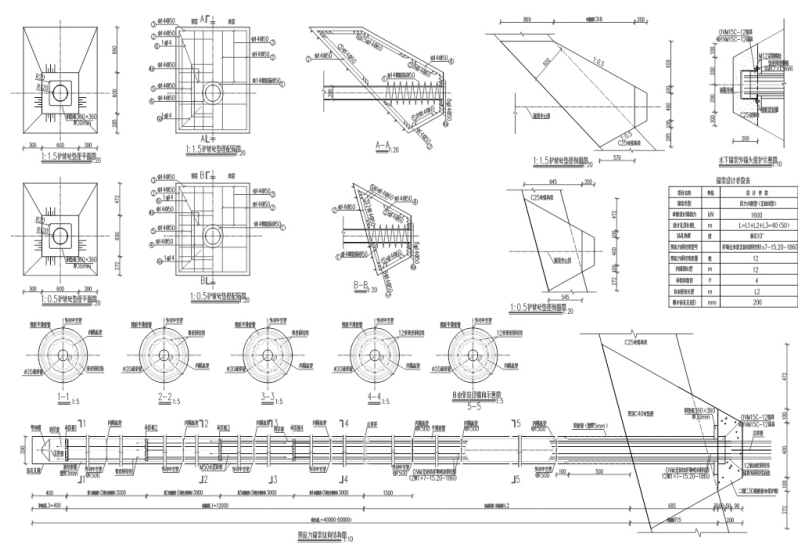

图 2 边坡针索支护结构

\section{2 施工流程和施工方法}

\section{2 .1 测量放样}

测量人员根据图纸确定针索孔的位置, 并用钢钎进行标 记, 以方便后续的施工。由于本工程中针索的数量非常多, 进 行测量放线时, 一次标记的孔位数量不宜过多, 按照施工队伍 的施工能力进行布置即可 ${ }^{[2]}$ 。

在进行测量放样过程中, 应当由两人进行, 其中一人负责 布置孔位, 另一人则负责校对。在孔位布置完成后, 应当由监 理工程师进行审查 ${ }^{[3]}$, 合格后方可进行下一步施工工序。

\section{2 .2 浮渣和石块的清理}

在进行边坡支护之前, 施工人员应当对其中的浮渣、碎 石、石块和垃圾等进行彻底的清理, 确保边坡整洁干净后再进 行施工。由于本工程中的边坡坡度较大, 清理工作只能由人工 进行, 机械无法在大坡度的坡面上工作。

\section{2 .3 搭设脚手架}

坡面清理完成后在其上搭设脚手架, 搭设的最高高度为 $10 \mathrm{~m}$ 。脚手架立杆的纵向距离为 $1.8 \mathrm{~m}$, 横向距离为 $1.5 \mathrm{~m}$ 。脚手 板采用竹片或者厚木板制成, 每搭设一层脚手架, 铺设一层脚 手板。脚手架的钢管选择 $\phi 48 \mathrm{~mm} \times 3 \mathrm{~mm}$ 的钢管, 剖面作业图如 图 3 所示。

\section{2 .4 针索施工}

针索施工的钻孔过程采用液压针索钻机, 钻孔直径为 $200 \mathrm{~mm}$ 。由人工将钻孔机搬运到施工平台上进行安装, 调整钻 孔机使得其钻孔方向和孔位方向一致并使其足够稳固。在钻 进完成后, 质检员应当对成孔的参数进行测试, 判定该孔是否 为合格的孔。正常来说, 钻孔位置的偏差不能超过 $10 \mathrm{~cm}$, 孔的 直径的误差不能小于 $1 \mathrm{~cm}$, 孔的深度的误差不能大于 $20 \mathrm{~cm}$, 孔 的方位角偏差不能超过 $1^{\circ}$, 当验收合格后才能进行下一个孔的

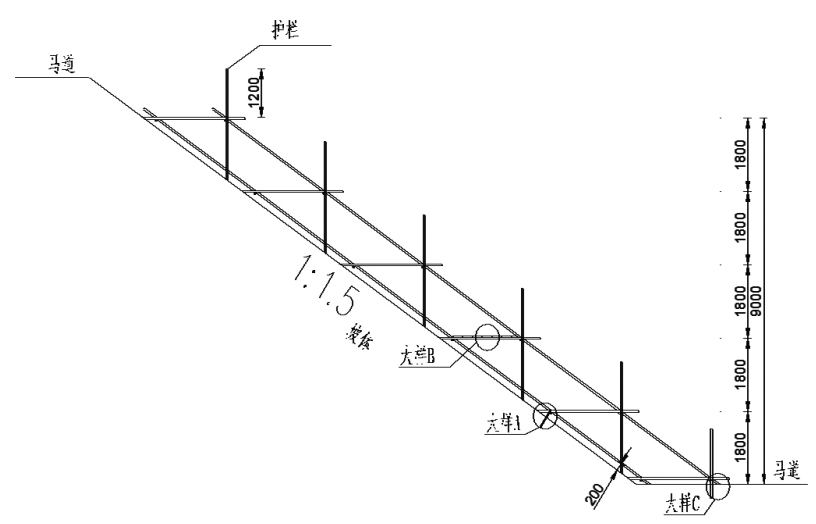

图 3 脚手架剖面作业图

钻进, 否则应当将孔填实后重新进行钻进 4 。

\section{2 .5 针索的制作和安装}

本工程采用的针索为分散型针索, 无黏结压力, 每段针索 的最大承受拉力为 $400 \mathrm{kN}$ 。制作针索的钢绞线的强度为 $1860 \mathrm{MPa}$, 属于较高强度, 钢绞线的直径为 $15.2 \mathrm{~mm}$ 。在编束钢 绞线之前, 施工人员应当详细检查钢绞线是否存在锈蚀、弯 折、变形、裂纹等问题, 应当保证用于制作针索的钢绞线无任 何质量问题。

切割钢绞线时应当采用砂轮切割机缓慢切割, 重点保证 切口的平整光滑, 严禁为节省时间直接使用气焊或电焊切割 钢绞线。

将处理完毕的钢绞线运输到坡上的加工平台上, 并按照 编束钢绞线的规定对其进行编号, 按照编号对应编束。编束钢 绞线时使用支架和束线环辅助进行，支架的间距应当大于 $1.5 \mathrm{~m}$, 同时在针索体中安装 $\phi 20 \mathrm{mmPVC}$ 注浆管与针索杆体绑 扎在一起, 在编束完成后检查针索是否存在扭转、交错等影响 质量的问题。

在钢绞线编束完成后开始安装针索, 首先在钻好的孔中 通人高压气流进行清理,将孔内的残渣等吹出孔外。当向孔中 持续吹气 $5 \mathrm{~min}$ 后仍未有残渣排出时说明孔已经清理完毕。

安装针索的过程中采用人工穿索, 在安装过程中应当注 意针索和注浆管之间的位置关系, 应当保证在穿索完成后注 浆管完好。如果出现注浆管不通畅或穿索过程中受阻, 应当将 钢索拔出并检查孔内, 排除障碍因素后再次进行施工。

\section{2 .6 注浆施工}

在针索安装完成后利用预先安装的注浆管进行注浆施 工, 考虑到本工程中针索的长度和孔的深度, 注浆应当一次性 完成。浆液的材料为 $\mathrm{P} \cdot \mathrm{O} 42.5 \mathrm{R}$ 的硅酸盐水泥, 浆液的水灰比 控制在 $0.4: 1$, 其中水泥结石体 $5 \mathrm{~d}$ 抗压强度不低于 $40 \mathrm{MPa}$, 在 浆液制备完成后, 应当进行水灰比实验, 合格后方可使用。注 
工程施工技术 Engineering Construction Technology

浆过程中应当安装自动记录仪进行记录, 也可采用人工方式 记录。

注浆所使用的设备为 3SNS-A 型灌浆百, 注浆的压力控 制在 $0.3 \sim 0.5 \mathrm{MPa}$, 一次性完成注浆, 中途不能中断。

\section{2 .7 针索张拉}

在张拉针索之前首先加工针墩, 针墩由钢垫板、钢套管、 和固定组件等构成, 其中钢垫板的规格为 $36 \mathrm{~cm} \times 36 \mathrm{~cm}$ 。针墩 整体由 C40 混凝土浇筑而成, 可以在混凝土中加人少量的减 水剂满足针索张拉时承载拉力的需要。

张拉针索的主要设备是 YCW200t 型千斤顶, 整个张拉过 程分为 3 个阶段, 首先是预张拉, 此时的拉力为 $30 \sim 50 \mathrm{kN}$, 其 作用为充分拉伸钢绞线使其完全平直，同时将张拉后的钢绞 线固定在针墩上。

预张拉完毕后是分级张拉, 共计分为 5 级, 分别是 $0 \%$ $40 \% 、 40 \% \sim 60 \% 、 60 \% \sim 80 \% 、 80 \% \sim 100 \%$ 和 $100 \%$ 105\%。在张 拉的过程中, 应当注意时刻测量针索的伸长量, 当伸长量能够 稳定 $5 \mathrm{~min}$ 后开始下一级的张拉过程。
如果张拉完毕后发现针索的预应力损失过大, 超过预定 值的 $10 \%$, 则应当进行补偿张拉, 确保钢绞线的实际伸长量 和理论计算的伸长量基本相符, 误差应当控制在 5\%以内。

\section{4 结语}

论文对高边坡预应力针索的安装施工过程进行了阐述和 分析, 其中重点是针索的制作和安装过程, 同时在施工过程中 应当注意各项参数的精度, 如孔的参数以及制作的针索的参 数等。同时,论文阐述了施工质量的保证措施。

\section{参考文献}

[1]连晓宏.预应力针拉桩板墙施工技术在道路高边坡支护中的 应用[J].低碳世界,2020,10(2):62-64.

[2]孙春艳. 大型高边坡支护处理设计方案比选研究[J]. 中国水运 (下半月),2019,19(6):213-215.

[3]黄勇博,王博生. 某泥岩砂岩互层高边坡监测与稳定性分析 [J]. 工程技术研究,2019,4(6):213-214.

[4]肖美,肖玉成. 全黏结预应力针索在老挝南康 3 水电站厂房高 边坡支护中的应用[J].四川水力发电,2018,37(3):68-70+117.

\section{（上接第 117 页）}

针筋总截面面积应满足规范要求:

$$
\begin{gathered}
A_{s} \geqslant \frac{V-0.3 N}{a_{r} a_{v} f_{y}}+\frac{M-0.4 N z}{1.3 a_{r} a_{b} f_{y} z}=2355 \mathrm{~mm}^{2} \\
A_{s} \geqslant \frac{M-0.4 N z}{0.4 a_{r} a_{b} f_{y} z}=0 \mathrm{~mm}^{2}
\end{gathered}
$$

式中, $a_{r}$ 为针筋层数影响系数, 4 层为 $0.85 ; a_{b}$ 为针板弯曲变 形的折减系数, $a_{b}=0.6+0.25 \frac{t}{b}=0.6+0.25 \times \frac{25}{20}=0.85 ; a_{v}$ 为针筋 受剪承载力系数, $a_{v}=(4-0.08 d) \sqrt{\frac{f_{c}}{f_{y}}}=(4-0.08 \times 20) \sqrt{\frac{14.3}{300}}=$ $0.524 ; z$ 为外层针筋中心线距离, 取 $390 \mathrm{~mm}$ 。

计算表明预埋件针筋 $12 \phi 20=3770 \mathrm{~mm}^{2}>A_{s}=2355 \mathrm{~mm}^{2}$, 计 算结果满足要求。

\section{6 拱形连续梁桥三角区施工流程}

步骤一: 主墩施工完成后, 搭设支架, 施工永久制作及临 时固结, 安装模板。

步骤二: 在主墩两侧的满膛支架上绑扎 $V$ 腿钢筋, 将临 时铰上支座预埋件固定于 $\mathrm{V}$ 腿钢筋下端, 通过销轴把临时铰 上支座下支座销住, 形成临时转铰。

步骤三: 两侧对称浇筑 $\mathrm{V}$ 腿及梁拱结合处混凝土, 将临
时铰下支座预埋件固结在 V 腿混凝土的端部。

步骤四: 搭建 $0^{\#}$ 块上部箱梁支架并进行预压, 预压合格 后开始钢筋、预应力安装及混凝土施工。

步骤五: 箱梁强度达到要求后, 浇筑在临时铰混凝土, 待 混凝土强度达到设计要求后, 进行箱梁预应力张拉、压浆工 序, 开始后续箱梁施工。

\section{7 结语}

耳板销轴式临时铰有效解决了传统垫块式临时铰只能释 放弯矩、不能限制梁体坚向位移的问题。刚性临时铰不仅能承 受较大的轴向力、剪力, 传力、释放弯矩性能良好, 同时有效地 限制了梁体坚向位移, 达到既有效避免混凝土裂缝产生, 又避 免混凝土错台的效果, 更加有利地保障了桥梁线性的连续性, 保证了梁体质量。

\section{参考文献}

[1]胡川开, 汪芳, 江军. 大跨度拱形连续梁桥设计与施工关键技术 [J].现代交通技术,2013,10(2):45-48.

[2]中华人民共和国住房和城乡建设部.混凝土结构设计规范:GB 50010-2010[S].北京:中国建筑工业出版社,2015.

[3]中华人民共和国水利部.水利水电工程钢闸门设计规范:SL742013[S].北京:中国水利水电出版社,2013. 